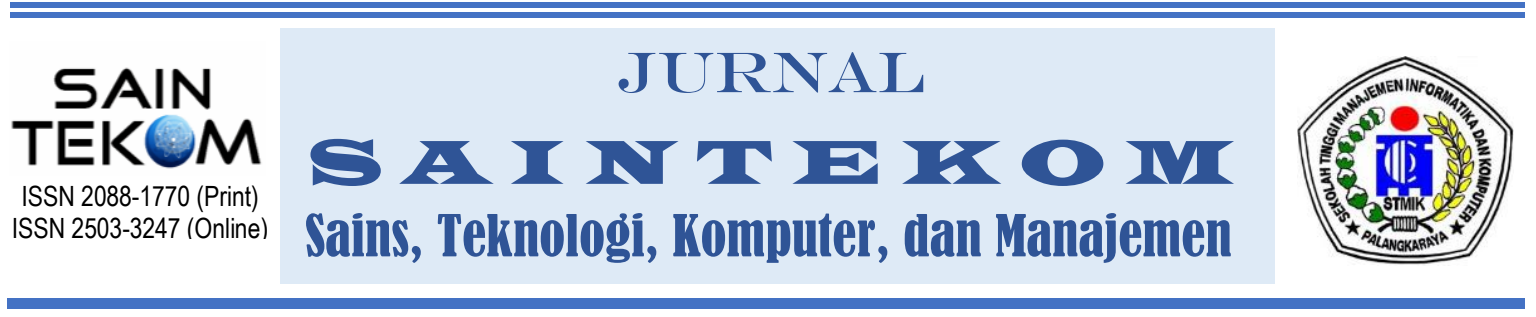

\title{
TERAPAN MCRNG SEBAGAI GENERATOR ACAK UNTUK GAME
}

\author{
*Usman Nurhasan ${ }^{1}$, Bagus Purnomo ${ }^{2}$ \\ 1,2) Jurusan Teknologi Informasi Politeknik Negeri Malang \\ Jalan Soekarno Hatta No.9 Kota Malang \\ Email: usmannurhasan@polinema.ac.id, bagustebuan@gmail.com
}

\begin{abstract}
Most game s are used as a means of entertainment, but can also function as a means of training, education and simulation. In the field of education, educational game s can be applied by adopting educational materials to be informed in an interesting way to users. To provide a challenge to the user, the concept of level and scoring is applied in the game. The type of game made is a quiz-based educational game. Elements of educational game s made in the form of text, images, sounds and videos regarding knowledge about the classification of vertebrate and invertebrate animals. The data and answers used in the quiz are also displayed in a random way. The randomization process uses a random generator that applies the concept of Multiplicative Congruential Random Number Generator (CRNG). The use of this generator is intended so that users get different questions and answer compositions at each level. This is so that the user does not get bored quickly and the game becomes more interesting to play. So that the user indirectly conducts learning activities because the information conveyed is in the form of knowledge that is packaged in the form of a game.
\end{abstract}

Keywords : Animal Recognition, Educational, Game, MCRNG, Random Generator

\begin{abstract}
ABSTRAK
Kebanyakan game difungsikan untuk sarana hiburan,akan tetapi dapat juga berfungsi sebagai sarana latihan,pendidikan dan simulasi. Pada bidang pendidikan, terapan game edukasi dapat dengan mengadopsi materi-materi pendidikan untuk diinformasikan secara menarik kepada user. Untuk memberikan tantangan kepada user, dalam game diterapkan konsep level, dan skoring. Jenis game yang dibuat berupa game edukasi berbasis quis. Unsur game edukasi yang dibuat berupa text, gambar, suara dan video menegnai pengetahuan tentang klasifikasi hewan vertebrata dan avertebrata. Data dan jawaban yang digunakan dalam quis juga ditampilkan dengan cara acak. Proses pengacakan menggunakan generator acak yang menerapkan konsep Multiplicative Congruential Random Number Generator (CRNG). Penggunaan generator ini dimaksudkan agar user mendapatkan soal dan komposisi jawaban yang berbeda di tiap levelnya. Hal ini bertujuan agar user tidak cepat merasa bosan dan game menjadi lebih menarik untuk dimainkan. Sehingga user secara tidak langsung melakukan aktifitas belajar karena informasi yang disampaikan berupa pengetahuan yang dikemas dalam bentuk permainan.
\end{abstract}


Kata kunci : Edukasi, Game, Generator Acak, ,MCRNG, Pengenalan Hewan

\section{PENDAHULUAN}

Saat ini penggunaan smartphone tidak hanya digunakan sebagai alat komunikasi. Melainkan sebagai media penunjang kehidupan manusia hal ini beriringan dengan semakin canggih dan kompleks nya fitur-fitur yang ada di dalam smartphone itu sendiri. Smartphone / ponsel pintar memiliki fitur pendukung termasuk internet, aplikasi game, email, pemutar musik, dan bluetooth. Ponsel juga seringkali digunakan sebagai perangkat untuk memainkan game mobile.

Kebanyakan game difungsikan untuk sarana hiburan,akan tetapi dapat juga berfungsi sebagai sarana latihan,pendidikan dan simulasi. Trend game sebagai media edukasi semakin tinggi sehingga hampir semua materi yang bersifat edukasi di implementasi kan dalam sebuah game. Berdasarkan hal tersebut, peneliti merancang dan menerapkan sebuah game edukasi dengan tema pengetahuan tentang klasifikasi hewan vertebrata dan invertebrata . Pemilihan tema ini bertujuan untuk mempermudah user dalam mengenali dan mempelajari klasifikasi hewan yang beraneka ragam.
Game yang baik adalah game yang dapat membuat user tertarik dan tidak bosan untuk terus memainkan. Hal utama untuk menciptakan suasana tersebut adalah dengan memberikan tantangan pada setiap skenario game . Salah satu bentuk tantangan yang dapat diterapkan adalah adanya soal, penentuan level dan waktu. Skenario yang diterapkan game ini bertujuan untuk memicu kemampuan menebak gambar hewan berdasarkan suara, kategori, makanan, dan klasifikasinya.

Informasi yang ditampilkan dalam game ini berupa teks, gambar dan suara yang merupakan representasi dari pengetahuan tentang klasifikasi hewan. Informasi tersebut diwujudkan dalam bentuk soal quis. Pemain game akan lebih tertarik jika terdapat sebuah tantangan pada sebuah game. Tantangan tersebut dapat berupa level dan keragaman jenis soal. Pertanyaan dalam bentuk soal akan dimunculkan secara acak agar tidak mudah ditebak. Konsep pengacakan yang digunakan menggunakan MCRNG sebagai generator pengacakan. Game ini memiliki beberapa tingkat kesulitan, skor, dan batas waktu. Tingkat kesulitan 
meliputi level 1, level 2, dan level 3 . Sedangkan penilaian diperoleh dari tebakan pengguna dalam game berdasarkan gambar, makanan, dan kelas hewan yang dipilih. Level I diberikan dalam waktu 5 menit dengan 15 skor benar dan 5 skor salah, sedangkan level II harus diselesaikan dalam 4 menit dengan 10 skor benar dan 10 skor salah, sedangkan level III diberikan dalam 3 menit dengan 5 skor benar dan 15 skor salah.

\section{METODE}

\subsection{Metodologi Penelitian}

Pengembangan aplikasi ini dilakukan dengan menerapkan metodologi Multimedia Development Life Cycle (MDLC). Ada enam tahapan dalam MDLC, yaitu: konsep, desain, pengumpulan material, perakitan, pengujian, dan distribusi (Sakurai and Murayama, 2019). Langkah-langkah yang dilakukan dalam metodologi tidak harus dilakukan secara berurutan karena setiap tahapan memiliki proses yang saling terkait satu sama lain. Meski begitu, tahap konsep harus menjadi hal pertama yang harus dilakukan.

Data yang digunakan dalam penelitian ini adalah data suara, data pakan, data kelas hewan. Sedangkan data citra hewan terdiri dari dua kategori yaitu vertebrata dan invertebrata . Pengolahan data dilakukan sesuai dengan aturan permainan edukasi dan papan cerita. Aturan yang diterapkan dalam penerapannya mengadopsi dasar pengetahuan dari ilmu Biologi khususnya tentang klasifikasi hewan. Tahapan pengujian perangkat lunak dilakukan dengan menggunakan UAT (User Acceptance Test). Pengujian dilakukan oleh pengguna berupa siswa sekolah dasar dan guru. Ini dilakukan untuk mendapatkan umpan balik dari pengguna secara langsung. Umpan balik dari pengguna akan digunakan untuk pengembangan perangkat lunak lebih lanjut.

\subsection{Generator Acak}

Nomor acak adalah nomor apa saja; Namun, mereka tidak sembarangan. Angka acak tidak dapat diprediksi (Zeller and Neuhaus, no date). Tidak ada bilangan acak yang benar-benar menghasilkan bilangan sempurna (Rahman, 2016). Random Number Generator adalah algoritma yang digunakan untuk menghasilkan urutan atau urutan angka hasil perhitungan komputer yang diketahui terdistribusi sehingga angka tersebut 
muncul secara acak dan digunakan terus menerus.

Generator nomor acak harus memiliki unsur-unsur seperti (Olu, 2012):

a. Distribusi seragam $(0,1)$ dan tidak ada korelasi antar angka.

b. Pembuatan cepat dan penyimpanan skala kecil.

c. Dapat di reproduksi.

d. Periode besar, karena ada kemungkinan untuk menghasilkan kembali angka acak.

Ada banyak Algoritma atau metode untuk menghasilkan bilangan acak; salah satunya adalah Multiplicative CRNG (Congruential Random Number Generator) (L'Ecuyer, 1994). Algoritma atau metode ini merupakan salah satu jenis Algoritma RNG (Random Number Generator) yang dibuat berdasarkan proposal. Algoritma/metode RNG adalah sebagai berikut:

$Z i=\left(a Z_{i-1}\right) \bmod m$

Dimana:

$\mathrm{Zi}=\mathrm{i}$-bilangan awal acak

Zi-1 = bilangan akhir

$\mathrm{a}=$ pengali

$\mathrm{m}=$ modulus kunci generator adalah Z0 yang disebut umpan.
Algoritma dalam game ini digunakan untuk mengacak pertanyaan, gambar, makanan, dan kelas hewan. Rumus dari Algoritma tersebut adalah sebagai berikut:

$Z i=\left(a Z_{i-1}\right) \bmod m$

Parameter yang digunakan adalah $\mathrm{Z}=$ $5, \mathrm{~m}=11$, dan $\mathrm{a}=2$.

Tabel 1. Algoritma CRNG

\begin{tabular}{|c|l|}
\hline $\begin{array}{c}\text { Urutan sebelum } \\
\text { diacak }\end{array}$ & \multicolumn{1}{c}{$\begin{array}{c}\text { Urutan setelah } \\
\text { diacak }\end{array}$} \\
\hline 1 & $2 \times 5 \bmod 29=10$ \\
\hline 2 & $2 \times 10 \bmod 29=9$ \\
\hline 3 & $2 \times 9 \bmod 29=7$ \\
\hline 4 & $2 \times 7 \bmod 29=3$ \\
\hline 5 & $2 \times 3 \bmod 29=6$ \\
\hline 6 & $2 \times 6 \bmod 29=1$ \\
\hline 7 & $2 \times 1 \bmod 29=2$ \\
\hline 8 & $2 \times 2 \bmod 29=4$ \\
\hline 9 & $2 \times 4 \bmod 29=8$ \\
\hline 10 & $2 \times 8 \bmod 29=5$ \\
\hline
\end{tabular}

Seperti yang ditunjukkan pada percobaan perhitungan di atas, tabel adalah hasil dari penggunaan metode Multiplicative CRNG. Dari 10 data sebelum bilangan tersebut diacak, terdapat bilangan berikut 1,2,3,4,5,6,7,8,9,10. Setelah angka diacak menggunakan Algorithm Multiplicative $C R N G$, didapatkan angka atau keluaran random 10,20,7,3,6,1,2,4,8,5. Seperti terlihat pada Tabel 1, dapat disimpulkan bahwa Algoritma Multiplicative CRNG dianggap berhasil menghasilkan 
bilangan unik yang akan digunakan sebagai media pengacakan soal pada game edukasi berbasis Android dalam menebak gambar hewan vertebrata dan invertebrate (Pencarian and Berbasis, 2014).

\subsection{Skenario Pengujian}

Pengujian sistem dilakukan dengan meliputi dua tahap yaitu pengujian Alpha dan Beta. Pengujian dilakukan untuk mengevaluasi hasil dari sistem yang dibuat. Pengujian black box diterapkan pada pengujian alpha. Proses pengujian awal dilakukan dengan menjalankan aplikasi, kemudian dilihat dalam menjalankan fungsi yang tersedia apakah terdapat kesalahan dalam pengujian menggunakan sekumpulan aktivitas validasi, dengan pendekatan pengujian black box.

Pengujian black box dilakukan dengan membuat test case yang bersifat mencoba semua fungsi dengan menggunakan software apakah sudah sesuai dengan spesifikasi yang dibutuhkan. Tahap pengujian selanjutnya adalah Beta yang melibatkan pengguna akhir; siswa sekolah dasar dari kelas 3 sampai kelas 6 dalam kuesioner disertakan. Rumus yang digunakan dalam pengujian kuesioner adalah sebagai berikut:

$$
\mathrm{H}=\frac{z}{J} * 100
$$

Penjelasan rumus sebagai berikut:

$\mathrm{H}=$ Hasil Perhitungan .

$\mathrm{Z}$ = Banyaknya jawaban responden untuk setiap pertanyaan.

$\mathrm{J}=$ Jumlah responden

\subsection{Perancangan Game}

Pada Gambar 1 dijelaskan proses pertama yang dilakukan yaitu masuk ke sistem, setelah data citra dimuat kemudian dilakukan proses pengacakan citra dengan menggunakan metode Congruential Random Number Generator (CRNG). Ada kondisi tertentu jika setiap pengguna menebak gambar dengan benar maka nilai tambah tetapi jika tebakan salah nilainya berkurang (Alfaris, Anam and Masy'an, 2013).

Kemudian permainan akan berlanjut ke level berikutnya, pada level ini terdapat perbedaan dengan yang sebelumnya, yaitu data gambar akan semakin lama semakin bertambah. Hal ini dilakukan agar setiap pengguna termotivasi untuk menjawab tebakan gambar dan suara dengan benar dengan cepat dan tepat, dengan adanya level dalam game ini akan membuat game menjadi lebih menarik dan pengguna tidak akan merasa bosan. 


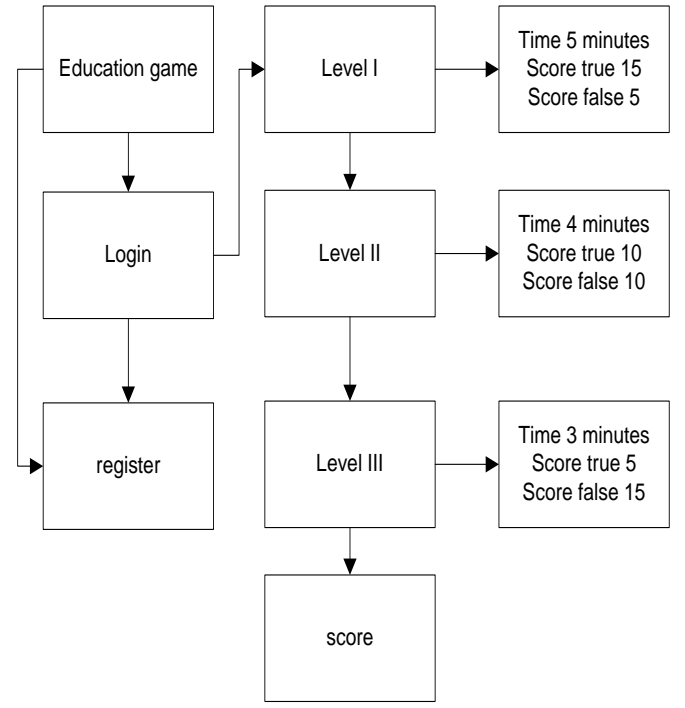

Gambar 1. Alur Game

Dari flowchart sistem pada

Gambar 2 terlihat bahwa alur dari user memulai permainan kemudian sistem melakukan proses permainan meliputi tingkat kesulitan, skor, dan batas waktu saat user memainkan sebuah game .(Goldstone, 2009). Tingkat kesulitan meliputi level 1, level 2, dan level 3.

Skor akan dinilai berdasarkan tebakan dari pengguna dalam menebak hewan berdasarkan gambar, makanan, dan kelas hewan. Level I diberikan dalam waktu 5 menit dengan 15 skor benar dan 5 salah, level II, sebaliknya, harus dilakukan dalam 4 menit dengan 10 skor benar dan 10 skor salah, sedangkan level III diberikan dalam 3 menit dengan 5 skor benar dan 15 skor salah.
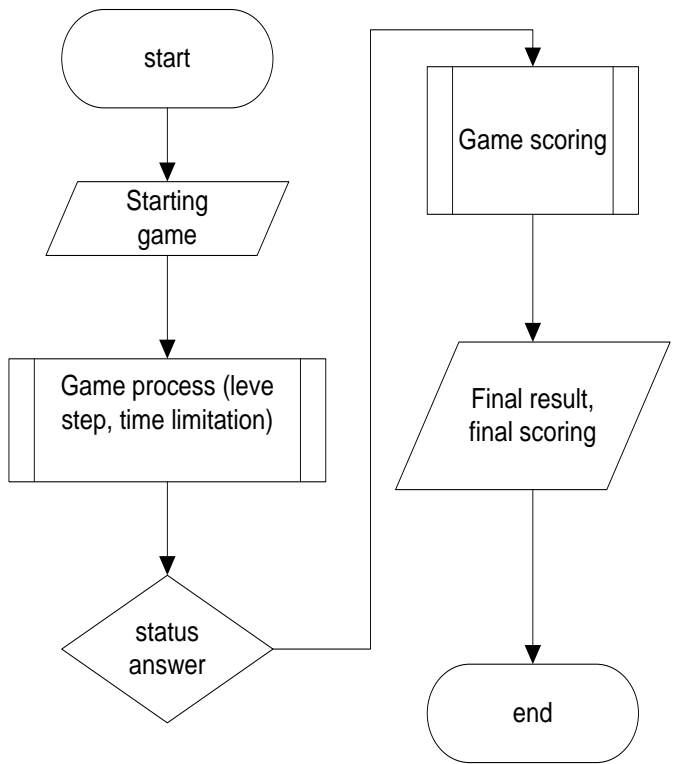

Gambar 2. Flowchart

Game ini menggunakan Unified Modeling Language sebagai pemodelan sistem, terdapat empat aktor pengguna dalam diagram use case yang ditunjukkan pada Gambar 3.

Penjelasan urutan desain diagram pada Unified Modeling Language adalah sebagai berikut: Gambar 4 menunjukkan diagram aktivitas login yang menggambarkan perilaku pengguna saat bermain game.

Pada gambar tersebut user melakukan tindakan dalam melakukan proses login. Pertama user mengisi data pada form login, kemudian sistem mengecek data username dan password yang telah dibuat oleh user, selanjutnya sistem akan melanjutkan ke halaman ruangan. 


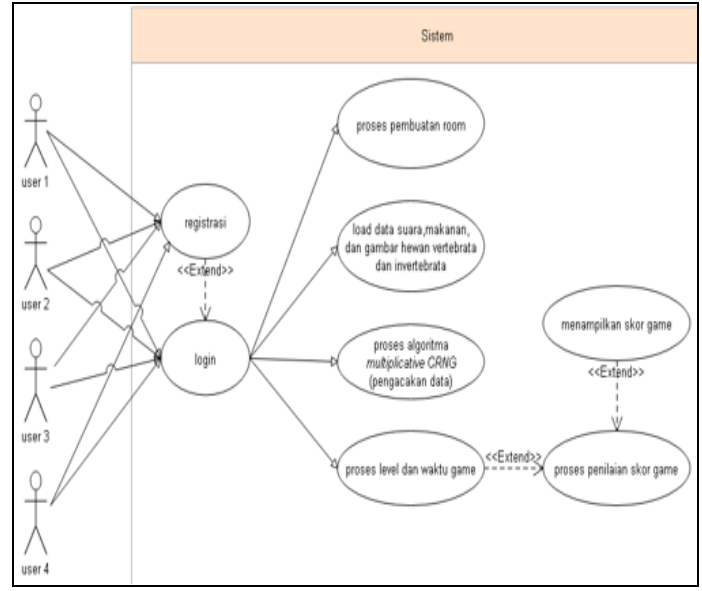

Gambar 3. Use case Diagram

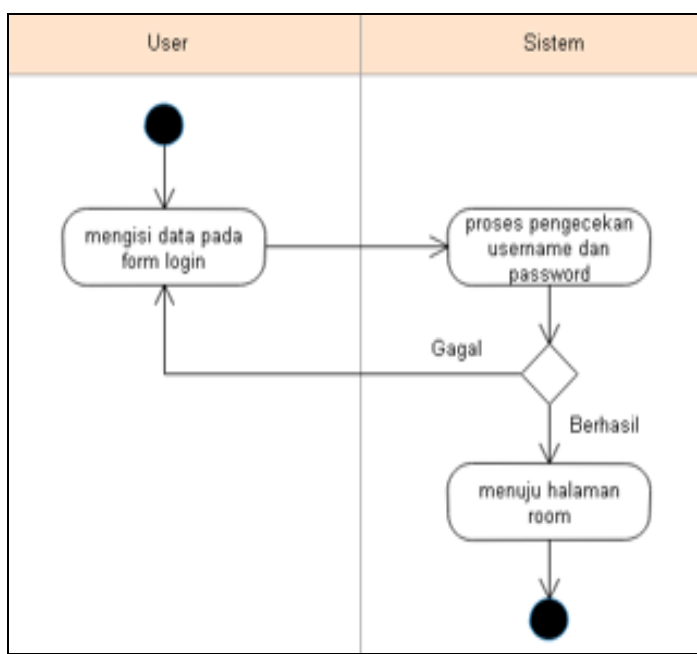

Gambar 4. Login Activity Diagram

Sequence diagram adalah diagram yang menggambarkan komunikasi antar objek dalam game yang akan dibuat. Diagram ini menunjukkan urutan interaksi yang dilakukan oleh objek-objek dalam sebuah game. Gambar 5 menggambarkan perilaku pengguna dalam memasuki sistem permainan. Digunakan untuk menampilkan kelas dan paket dalam sistem dan memberikan gambaran tentang sistem secara statis dan hubungan. Beberapa diagram akan menampilkan subset dari kelas-kelas dan hubungannya dapat dibuat beberapa diagram sesuai dengan yang diinginkan untuk mendapatkan gambaran lengkap dari sistem yang dibangun. Pada level class diagram desain ini ada 5 kelas yang digunakan.

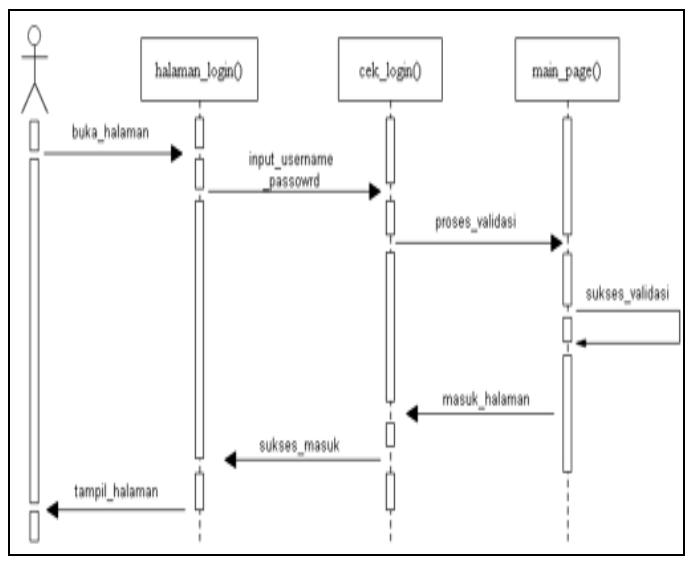

Gambar 5. Sequence Diagram

Data yang diolah dalam dalam game tersimpan dalam database. Setiap output level dalam permainan akan tersimpan dan di tampilkan sebagai informasi untuk pengguna. Pada tabel 2 ditampilkan tabel struktur user.

Dapat dilihat pada tabel 2, tabel data user memiliki 5 field dengan tipe field yang berbeda. Isi tabel meliputi id_user, email, password, kode, dan status yang berfungsi untuk menampung data pengguna. Kunci utama dalam tabel ini adalah bidang id_user. 
Tabel 2. Struktur Data Tabel User

\begin{tabular}{|l|l|l|}
\hline Nama_Field & Type Field & Length \\
\hline Id_user & Int & 11 \\
\hline Email & Varchar & 255 \\
\hline Password & Varchar & 255 \\
\hline Code & Varchar & 255 \\
\hline Status & Enum & 'Y', 'N' \\
\hline
\end{tabular}

Data hewan untuk materi edukasi dapat dilihat pada Tabel 3 . Tabel tersebut memiliki 5 field. Kolom di sini meliputi id_hewan, nama, suara, gambar, dan kategori id_ yang berfungsi untuk menampung data hewan. Primary key pada tabel ini adalah id_ animal sedangkan foreign key untuk menghubungkan ke tabel kategori yaitu id_category.

Tabel 3. Struktur Data Tabel Animal

\begin{tabular}{|l|l|l|}
\hline \multicolumn{1}{|c|}{ Name Field } & Type Field & Length \\
\hline Primer_Id_animal & Int & 11 \\
\hline Name & Varchar & 255 \\
\hline Voice & Varchar & 255 \\
\hline Picture & Varchar & 255 \\
\hline Id_category & Int & 11 \\
\hline
\end{tabular}

Data proses multiclient dalam permainan disimpan dalam tabel 4 . Tabel data room yang memiliki 4 field dengan tipe field yang berbeda. Empat (4) field dengan tipe field yang berbeda antara lain id_room, id_detail, id_user, dan score yang berfungsi untuk menampung data detail room. Primary key pada tabel ini adalah id_detail, sedangkan foreign key adalah id_room dan id_user yang digunakan untuk menghubungkan tabel user dan tabel room.

Tabel 4. Struktur Tabel Data Room

\begin{tabular}{|l|l|l|}
\hline Name_Field & Field Type & Length \\
\hline Id_detail & Int & 11 \\
\hline Id_room & Int & 11 \\
\hline Id_user & Int & 11 \\
\hline Score & Int & 11 \\
\hline
\end{tabular}

\section{HASIL DAN PEMBAHASAN}

\subsection{Implementasi Aplikasi}

Gambar di bawah menunjukkan hasil implementasi sistem. Gambar 6 merupakan tampilan keseluruhan dari game edukasi berbasis android dalam menebak gambar hewan vertebrata dan invertebrata, yang menampilkan tampilan untuk login, list room, play game, dan skor atau peringkat pengguna. 


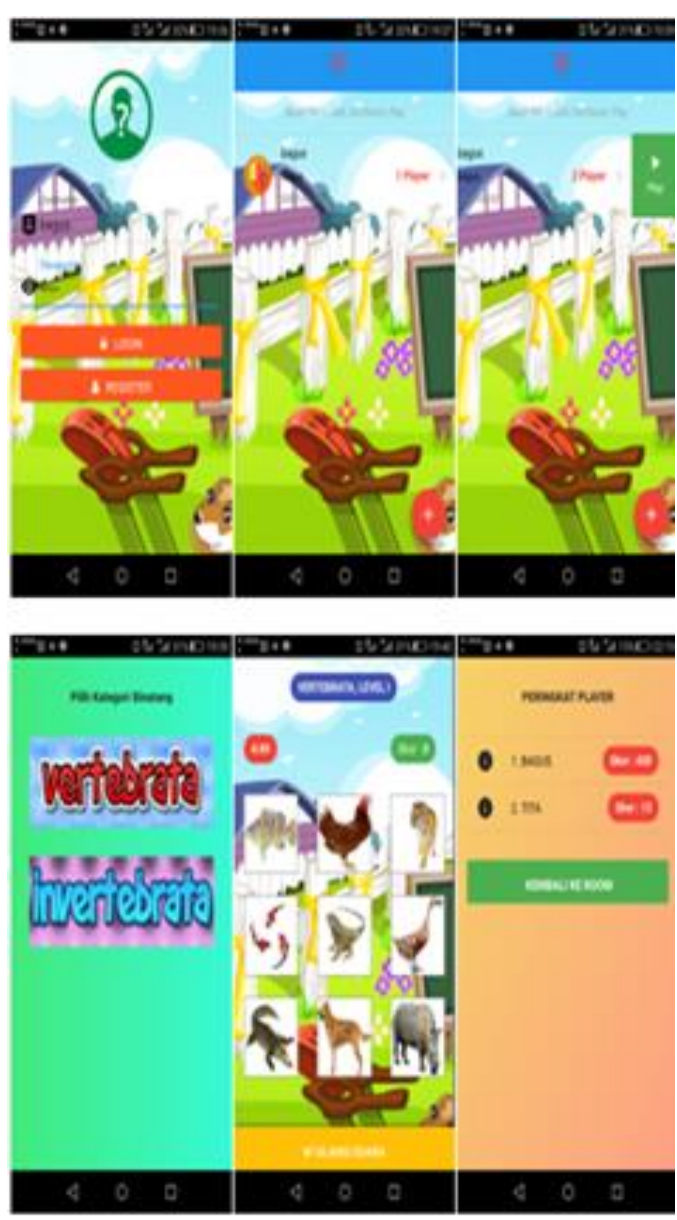

Gambar 6. User Interface Game

\subsection{Terapan Algoritma MCRNG}

Berikut tabel hasil perhitungan randomisasi game level 1

Tabel 5. Uji coba Generator Level 1

\begin{tabular}{|c|c|}
\hline Algorithm & Multyplicative CRNG \\
\hline Parameter & $\mathrm{Z} 0=5, \mathrm{a}=2, \mathrm{~m}=37$ \\
\hline Level & 1 (one) \\
\hline $\begin{array}{l}\text { Amount of } \\
\text { Data }\end{array}$ & 36 \\
\hline $\begin{array}{l}\text { Results } \\
\text { Random } \\
\text { Numbers }\end{array}$ & $\begin{array}{l}10,20,3,6,12,24,11,22,7, \\
14,28,19,1,2,4,8,16,32, \\
27,17,34,31,25,13,26,15, \\
30,23,9,18,36,35,33,29, \\
21,5\end{array}$ \\
\hline $\begin{array}{l}\text { Number of } \\
\text { questions } \\
\text { taken }\end{array}$ & 10 indexes from index 1 \\
\hline
\end{tabular}

Tabel di bawah ini menunjukkan hasil perhitungan pada pengacakan game level 2

Tabel 6. Uji coba Generator Level 2

\begin{tabular}{|l|l|}
\hline Algorithm & Multyplicative CRNG \\
\hline Parameter & $\mathrm{Z} 0=5, \mathrm{a}=2, \mathrm{~m}=37$ \\
\hline Level & 2 (two) \\
\hline $\begin{array}{l}\text { Amount of } \\
\text { Data }\end{array}$ & 36 \\
\hline $\begin{array}{l}\text { Results } \\
\begin{array}{l}\text { Random } \\
\text { Numbers }\end{array}\end{array}$ & $\begin{array}{l}10,20,3,6,12,24,11,22,7, \\
27,17,34,1,2,4,8,16,32, \\
30,23,9,18,36,35,33,29, \\
21,5 \text { The }\end{array}$ \\
\hline $\begin{array}{l}\text { number of } \\
\text { questions } \\
\text { taken is }\end{array}$ & $\begin{array}{l}10 \text { indexes from the 11th } \\
\text { index the }\end{array}$ \\
\hline
\end{tabular}

Tabel berikut menunjukkan hasil perhitungan pada game level 3 .

Tabel 7. Uji coba Generator Level 3

\begin{tabular}{|l|l|}
\hline Algorithm & \multicolumn{1}{|c|}{ Multyplicative CRNG } \\
\hline Parameter & $\mathrm{Z} 0=5, \mathrm{a}=2, \mathrm{~m}=37$ \\
\hline Level & 3 (three) \\
\hline $\begin{array}{l}\text { Amount of } \\
\text { Data }\end{array}$ & 36 \\
\hline $\begin{array}{l}\text { Results } \\
\text { Random } \\
\text { Numbers }\end{array}$ & $\begin{array}{l}10,20,3,6,12,24,11,22,7, \\
27,17,34,31,25,13,26,15, \\
30,23,9,18,36,35,33,29, \\
35,33,29,21,5 \text { The }\end{array}$ \\
\hline $\begin{array}{l}\text { number of } \\
\text { questions } \\
\text { taken }\end{array}$ & $\begin{array}{l}10 \text { indexes from the 22nd } \\
\text { index }\end{array}$ \\
\hline
\end{tabular}

Algoritma CRNG perkalian yang digunakan mampu membuat indeks secara acak dengan parameter $\mathrm{z}$, a, dan modulus yang telah ditentukan (Pencarian and Berbasis, 2014). Pada game ini digunakan parameter $\mathrm{z}$ yaitu jumlah soal dari 1 sampai 36, kemudian parameter a, nilai yang ditentukan 2, 
dan modulus yang ditentukan 37 sehingga indeks suara dan gambar akan diacak tanpa indeks yang sama. Namun masih terdapat kelemahan pada Algoritma tersebut yaitu ketika parameter (z) yang digunakan sama maka posisi randomized index akan sama. Hasil pembangkitan bilangan acak kemudian diolah untuk membentuk atribut nilai pada setiap posisi indeks kartu dengan rumus seperti yang penulis jelaskan pada implementasi Algoritma Multiplicative CRNG.

\subsection{Uji coba Pengacakan Secara Default}

Fungsi acak yang digunakan di banyak aplikasi adalah fungsi acak default dari bahasa pemrograman. Peneliti mencoba membangkitkan bilangan bulat acak sebanyak 36 kali dengan menggunakan fungsi default random dari bahasa pemrograman yang akan digunakan yaitu java dengan kode sumber sebagai berikut:

random int $=($ int $)($ Math.random ()$* 36)$.

Tabel 8. Default Pengacakan

\begin{tabular}{|l|l|}
\hline \multicolumn{1}{|c|}{ Formula } & \multicolumn{1}{|c|}{ Random Results } \\
\hline (int) & $15,11,27,24,27,10,8,8,14,35$, \\
(Math.random & $19,16,36,20,36,24,21,24,34,3$ \\
()$* 36) ;$ & $6,22,24,35,28,26$, \\
& $26,30,30,36,30,35,35,35,36,3$ \\
& $5,36$. \\
\hline
\end{tabular}

Dari percobaan terlihat bahwa bilangan acak yang dibangkitkan dengan menggunakan fungsi default bahasa pemrograman masih belum optimal karena terjadi beberapa kali pengulangan bilangan yang sama secara berurutan.

\section{SIMPULAN}

Beberapa kesimpulan yang dapat diambil dari hasil tersebut adalah:

a. Sistem adalah game yang dapat melakukan proses join room, exit room, dan melakukan proses game secara multiplayer.

b. Metode pengacakan menggunakan Multiplicative Congruential Random Number Generator mampu memproses pengacakan indeks. Namun masih terdapat kelemahan pada Algoritma tersebut yaitu ketika digunakan parameter yang sama (z) maka posisi randomized index akan sama.

c. Multiplicative $C R N G$ adalah Algoritma yang baik untuk digunakan sebagai generator dan pengacakan gambar, pertanyaan dan suara dalam game edukasi berbasis android dalam menebak gambar hewan vertebrata dan invertebrata karena menghasilkan teka-teki unik setiap kali dihasilkan 
dan dapat diselesaikan dengan cepat.

\section{DAFTAR PUSTAKA}

Alfaris, H. B. I., Anam, C. and Masy'an, A. (2013) 'Implementasi Black Box Testing Pada Sistem Informasi Pendaftaran Santri Berbasis Web Dengan Menggunakan PHP dan MySQL', SAINTEKBU: Jurnal Sains dan Teknologi, 6(1), pp. 23-38.

Goldstone, W. (2009) Unity Game Development Essentials, Image Rochester NY.

L'Ecuyer, P. (1994) 'Uniform random number generation', Annals of Operations Research, 53(1), pp. 77-120. doi: 10.1007/BF02136827.

Olu, A. (2012) 'A Simulated Enhancement of Fisher-Yates Algorithm for Shuffling in Virtual Card Games using DomainSpecific Data Structures', International Journal of Computer Applications, 54(11), pp. 9758887. Available at: http://citeseerx.ist.psu.edu/viewdoc/ download?doi=10.1.1.259.114\&rep $=$ rep1\&type $=$ pdf.

Pencarian, D. A. N. and Berbasis, O. (2014) 'Aplikasi permainan asteroid shooter menggunakan mcrng dan $a^{*}$ sebagai algoritma randoming spawn dan pencarian objek berbasis mobile skripsi'.

Rahman, A. (2016) 'Pengacakan Random Sampling Dengan Pendekatan Inverse-Transform Random Variate Generator Berbasis', (July).
Sakurai, M. and Murayama, Y. (2019) 'Information technologies and disaster management - Benefits and issues -', Progress in Disaster Science. The Authors, 2, p. 100012. doi: 10.1016/j.pdisas.2019.100012.

Sweet, E. (2016) 'Information systems auditing: tools and techniques', ISACA Journal, pp. 01-18. Available at: https://www.isaca.org/COBIT/Doc uments/IS-auditing-creating-auditprograms_whp_eng_0316.pdf.

Zeller, A. and Neuhaus, S. (no date) 'Random Number Generator Designs', St.Cs.Uni-Saarland.De. Available at: http://www.st.cs.unisaarland.de/edu/secdesign/randgen. pdf. 